\title{
Strategic Alliance: Competitiveness of Sino-Foreign Cooperative School Running Operation
}

\author{
Lihui Xie \\ School of Inter-cultural Studies, Jiangxi Normal University, Nanchang 330022, China \\ E-mail: lhxie2111@126.com \\ Tao Hou
}

Department of International Exchange and Cooperation, Jiangxi Normal University, Nanchang 330022, China

E-mail: hout2004@sina.com

$\mathrm{Ze} \mathrm{Li}$

Resource and Architectural Engineering Department

Liaoning Institute of Science and Technology, Benxi 117022, China

E-mail: li.ze@sohu.com

Project: one of the accomplishments of a social science project of the eleventh Five-Year Plan (2008) of Jiangxi Province (No. 08jy63)

\begin{abstract}
Lying in a transformation period of economic development, economic prosperity, social progress and development in science and technology have to rely on strong competitiveness of a nation's universities to a large degree. Actually, universities' competitiveness is closely related to the improvement of a nation's competitiveness in human resources, industrial development and its comprehensive strength. From the perspective of universities' international strategic alliance, this paper analyzes the ways to improve Chinese universities' competitiveness as well as its components based on the theory of improving international competitiveness through Sino-foreign cooperative school operation.
\end{abstract}

Keywords: Strategic alliance, Sino-foreign cooperative school operation, Universities' competitiveness

With the globalization of modern economy and the enhancement of university effects all over the world, it has become a necessary tendency of educational internationalization to guarantee and strengthen Chinese universities' international competitiveness during economic transformation, to get ride of the danger of marginalization, to construct first-class universities and to conduct strategic alliances for international cooperation in educational field.

\section{The Development of Chinese Universities and the Request of Internationalization}

In the past 30 years since reform and opening, China's higher education has gone through three stages: the first one involves institutional reform and structural adjustment during which institutional reform and college amalgamation are the main tasks; the second period involves rapid development during which it is proposed to achieve coordinative development of scale, structure, quality and benefit. Nowadays, Chinese college student population has been enlarged from 1,900,000 to over 25,000,000, forming higher education with the largest scale in the world and entering the stage of mass higher education. After that, higher education reform enters the third stage in which educational reform gets deepened and teaching quality is improved. The gross enrollment rate of higher education has increased from $9.8 \%$ in 1998 to $24 \%$ at present. The overall scale of Chinese higher education has vaulted to top of the world. However, the speed-up of mass higher education has caused severe shortage of higher education resources.

Meanwhile, it is the globalization of modern economy and China's entry into WTO that pose new request for China's modern higher education reform and talent cultivation, making the internationalization of higher education an inevitable trend. With current multi-polar political pattern and diversified world culture, universities are playing a significant role in global cultural exchanges as the main institute for cultural production and delivery. Under such circumstances, international cooperative running of school becomes a school-running form conforming to internationalization, which establishes a favorable platform for reasonable use of good-quality teaching resources and expansion of excellent national culture.

\section{Cooperative Alliance Strategy: Sino-Foreign Cooperative Running of School.}

\subsection{General Analysis on Strategic Alliance}

Originating from 1980s, enterprise strategic alliance results from changes in competition environment brought about by economic globalization and attracted wide attention from economic and management fields, becoming a brand 
new research project.

(1) Definition of alliance: It refers to interrelation and connection based on certain strategic targets. As for its connotation, alliance should include both competition and cooperation among enterprises. It covers all business activities on the value chain in strategic management (Yuan, 2006).

(2) Definition of strategy: It refers to a series of activities chosen by enterprises to form unique value combinations to beat their rivals (Yuan, 2006).

(3) Definition of competition: Competition refers to the contest among manufacturers and other subjects of economic interest in order to obtain beneficial conditions for production and sale and therefore to earn greater economic benefit. It helps to improve the efficiency of all organizations (Xu, 2006).

(4) Connotation of strategic alliance: Two or more enterprises form an enterprise union or network through contracts or stock right participation based on mutual trust and benefit as well as complementation with independent management system and operation right in order to achieve common strategic targets or competitive advantages (Yuan, 2006).

Sino-foreign cooperation means strategic alliance of international cooperation with the best combination method in educational field in order to develop academic staff's practical skills, to support the development of subjects, to develop courses, to exert their respective advantages to the maximized extent through educational services, hence achieving the best benefit ultimately.

\subsection{The Significance of Cooperation for the Development of Chinese Higher Education}

Strategic alliance and cooperation are of particular importance to establish competitive advantages and maintain technical progress. Economic globalization, technical revolution, unutilized opportunities, open international market and its private nature have helped a greater number of companies to realize it is impossible for them to accomplish new market development only with their own resources and techniques. Therefore, they choose to establish strategic alliance and cooperation in order to gain clear channels through their joint market contracts. By doing so, they can make up their shortages in technology and manufacturing, perfect the effect of the supply chain, achieve market or scale economy (Thompson, 2006) and strengthen their domestic or international competitiveness.

In Sino-foreign cooperative running of school, by introducing foreign educational institutions' school running ideas, attracting excellent foreign teachers to participate in teaching, absorbing foreign educational resources, utilizing advanced teaching methods such as case teaching, class discussion, debate and demonstrative teaching, students will get in touch with and learn about the interactive and heuristic teaching methods adopted by foreign educational institutions and realize complementary advantages. Chinese universities actively narrow the disparity between their organization and conduction of educational projects and management and those in foreign ones, increase the variety and selectivity of educational supplies and improve teaching conditions and environment. In addition, cooperative running of school has also facilitated China's educational reform, quickened the steps of educational internationalization and established the cultivation goal that education should be geared to the world. In a word, Sino-foreign cooperative running of school is a beneficial complementation for China's school running forms, which helps to perfect and standardize China's higher education, hence quite important for China's educational industry.

\section{Sino-Foreign Cooperative School Running Pattern to Improve University Competitiveness}

\subsection{Connotation and Theory Analysis on University Competitiveness}

Among all theories on competitiveness, a widely accepted one is the theory raised by Michael Poter in Business College of Harvard University, who claims that productive elements are the basis for a series of elements of international competitiveness as well as that for the development of a nation or an area's competitiveness by putting competitiveness advantages against the background of market economy and world competition. Another one is the world competitiveness theory raised by International Management and Development College in Lausanne and World Economy Forum, which conducts comprehensive evaluation and analysis on a nation's comprehensive abilities in creating added value and creating increased national wealth with analysis targets and background targets (Song, 2005). It is its universities' competitiveness that determines the quality and level of productive elements of a nation directly or indirectly.

Meanwhile, universities' advance also depends on competition because it is competition that breaks the balance among universities. They get developed or eliminated in the process of balance-balance broken-balance. As a result, universities strengthen their efforts in creating specialties, hence facilitating the transmission of new ideas and technologies and promoting the development of education to a higher level. A university's competitiveness is manifested in the systematic integration of the correlation, inter-influence and restriction among all internal elements. Seen from its definition made by Chinese scholars, university competitiveness refers to the abilities made up of resources development ability, technical ability and management ability or a comprehensive integration formed by a 
university's specialties and advantages, unique school running ideas, excellent educational resources, dynamic academic atmosphere and campus culture.

\subsection{University Competitiveness Elements in Sino-Foreign Cooperative Running of School}

By absorbing foreign universities' excellent educational resources and advanced teaching management experience, taking the development of international technology as the core competitiveness and relying on the integration of strategic decision, knowledge production, marketing and organization and management, universities can achieve the ability in constant competitive advantages, which are mainly shown in five core competitive abilities.

\section{(1) Cultural Competition Ability}

The university is a place to inherit, practice and innovate culture. Culture refers to a kind of inheritable capital as well as values, moral standards, beliefs, business specialties, management styles and habits formed in practice through leaders' long-term proposal and staff's positive recognition, hence being of great value in itself. Special culture brought about by Sino-foreign cooperative running of school is characterized by bright feature of internationalization and tend to vary with the development of universities, hence stimulating them to have the ability in innovative development.

\section{(2) Learning Competition Ability}

Through Sino-foreign cooperation, universities have mutual understandings based on cognition, grasping and conveying of information and knowledge, which is beneficial for them to internalize the knowledge they have gained from the external environment. Such special knowledge, when transferred to the teaching process, strengthens the value and effect of teaching, endows universities with greater advantages compared with their rivals in the era of knowledge economy and helps them to be improved.

\section{(3) Innovative Competition Ability}

Innovative ability covers innovative spirit, innovative mechanism, knowledge preservation as well as innovative process to expand the invisible value of knowledge with higher uniqueness and unimitability. Through Sino-foreign cooperative running of school, universities can recombine, recreate and re-output knowledge based on their resources, constantly change or redesign themselves to be adjusted to constantly changing environment and offer continuous energy for their maintaining power in market competition in such a dynamic developing process.

\section{(4) Management Competition Ability}

Required by Sino-foreign cooperative running of school, project managers should stand at the world level and hold an international horizon when laying down goals and plans for educational reform. This refers to the abilities to make decisions, implement cooperative teaching practice and establish the direction of cooperation by conducting investigations on its educational guidelines, purposes, principles, course objectives, standards, teaching evaluation and development direction.

\section{(5) Talent Cultivation Competition Ability}

Universities are established and developed to cultivate talents and supply talents to our society. Through cooperation, Chinese universities have narrowed the disparity in organization and management of educational projects compared with western countries, increased the variety or selectivity of educational supplies, perfected teaching conditions and environment, promoted the diversification of talent cultivation patterns and cultivated complex talents needed in economic construction and social development.

\subsection{Ways to Improve Competitiveness through Sino-foreign Cooperative Running of School}

\section{(1) Sino-Foreign Cultural Communication}

Sino-foreign cooperative running of school serves as an important form of educational and cultural communication. As a school running pattern, Sino-foreign is also an accurate public article whose cultural value objectives should be penetrated into politics, economy, culture, science and technology through educational individuals. An open university will better display its diversification and innovative in cooperation against the background of Sino-foreign cultural interaction. As a result, compared with those conservative universities, universities based on Sino-foreign Cooperation tend to have greater advantages in constructing university culture.

\section{(2) Human Resources Development}

Sino-foreign cooperative running of school can also promote communication and cooperation between Chinese and foreign teachers. By sending teachers abroad for training and teaching with foreign teachers, Chinese teaches can rapidly improve their foreign language and professional levels in a short time; on the other hand, young teachers without the chance to go abroad have access to learning from foreign specialized teachers in terms of teaching contents and teaching methods. In addition, their knowledge on western culture and educational institution can be 
increased, hence making them the major teaching strength.

(3) Diversified Financing Patterns

Sino-foreign cooperation has attracted a large amount of foreign capital to invest in education in China; Social and folk capital are permitted to enter educational field in recent ten to twenty years. Some quoted companies of universities make it possible to combine financing and investment in Sino-foreign cooperative running of school so that onefold capital source for Chinese higher education can be solved.

(4) Combined Teaching System

Advanced foreign teaching patterns, such as multimedia classroom, network classroom, can be introduced to have joint teaching plans. Besides, this Sino-foreign combined teaching system and pattern should be adjusted to the current teaching environment of Chinese universities. In curriculum setting of cooperative running of school, students' language ability should be enhanced, specialized courses should complement for poor ones so as to cultivate complex talents with international communication ability and to enhance universities' competitive ability.

(5) Strengthening Internal Management System

There must be high-quality management staff in cooperative schools. By learning from foreign advanced experience, universities will reasonably arrange positions, clarify position duties, straighten out the relations among departments, design clear workflow in order to narrow the disparity between these cooperative universities' local environment with that in foreign counties (Gong, 2007).

(6) Complying with Market Demands

Universities are supposed to correctly tackle the relationship between market allocating resources and administrative macro control. Universities should have market mechanism in them to improve their resources allocation efficiency, to enhance cost restrictions and profit stimulation, to promote the financing demands of the subject of economic activities as well as to guarantee motivation for cooperative running of school ( $\mathrm{Hu}, 2008)$. The case of Sino-European International Business College attributes its success to satisfying enterprises' demands for talents by complying with market demands during its school running process.

\section{Conclusion}

International cooperation strategic alliance in education is intended to develop academic personnel's practical skills, support the development of specialties and curriculum, convert knowledge achievements, exert both sides' advantages with the best combination and to the largest extent and achieve the largest benefit ultimately by offering international educational services through Sino-foreign cooperative running of school. This is a necessary demand to improve talent quality during the process of international higher education and Chinese mass higher education against the background of economic globalization and diversified world culture. By establishing international cooperation partnership in education, we can not only deepen both sides' mutual understandings of educational system and strategic development and improve the organizational structure of educational institutes at all levels, but contribute to the improvement of university competitiveness and the growth of social economy according to actual business demands.

\section{References}

Arthur A. Thompson. Jr. Lan, Hailin (translator). (2006). Strategic Management: Earning Competitive Advantages. Beijing: China Machine Press.

China Educational News Web. Chinese and Foreign Presidents'Remarks on Talent Cultivation: Where Ability Lies in Education. [Online] Available: http://www.jyb.cn/high/gjsd/201005/t20100503_357318.html.

Gong, Siyi. (2007). Research on Universities' Sino-Foreign Cooperation Pattern and Operation Mechanism. Shanghai: Shanghai University Press.

Hu, Liangcai. (2008). Innovation in the Pattern of International Cooperative Running of School. Changsha: Hunan Normal University Press.

Song, Dongxia. (2005). Research on Chinese Universities' Competitiveness. Beijing: Higher Education Press.

Xie, Lihui. (2009). On Market Orientation of Sino-Foreign Cooperative School Running Based on Marketing Idea. China Market. (44).

Xu, Jianhua. Xu, Yuefei \& Guan, Binquan. (2006). School Competitiveness: Extraordinary Project of School Development. Shanghai: Shanghai Sanlian Bookstore.

Yuan, Xiaozhe. (2006). Theory and Practice of Strategic Alliance. Beijing: Economic Science Press. 